\title{
Clinical evaluation of efficacy and safety of transversus abdominis plane block with bupivacaine and ropivacaine for post-operative analgesia following lower segment caesarean section: A prospective, randomized, controlled, double blind study
}

\author{
Ravikumar Parmar ${ }^{1}$, Chandrika Bhut ${ }^{2 *}$, Lopa Trivedi ${ }^{3}$, Prashant Parmar ${ }^{4}$, Rajani Maulik Parikh \\ ${ }^{1,2}$ Assistant Professor, ${ }^{3,5}$ Associate Professor, ${ }^{4}$ Resident, ${ }^{1-3}$ Dept. of Anaesthesilogy, ${ }^{4}$ Dept. of Pharmacology, ${ }^{5}$ Dept. of Obstetrics \& \\ Gynecology, Government Medical College, Bhavnagar, Gujarat, India
}

\section{*Corresponding Author: Chandrika Bhut}

Email: dr.chandrika62@gmail.com

Received: $12^{\text {th }}$ December, 2018

Accepted: $6^{\text {th }}$ February, 2019

\begin{abstract}
Introduction: It is important for parturient to have less pain and to ambulate early in order to prevent venous thrombosis and to facilitate child care. Transversusabdominis plane (TAP) block is a recent peripheral nerve block technique which is used for the lower abdominal wall surgical procedure.

Materials and Methods: Study was carried out in 60 patients. Patients were randomly divided in two groups of 30 patients each by computer generated random no. method. After completion of caesarean section under spinal anesthesia, TAP block was given with 15 ml of $0.25 \%$ bupivacaine bilaterally in group Band with $15 \mathrm{ml}$ of $0.25 \%$ ropivacaine bilaterally in group R. Pain severity was measured by Visual Analog Scale. Total dose and frequency of rescue analgesics required in 24 hours, effect on hemodynamic variables, side effects \& complications if any were noted.

Result: VAS score have significantly less in group $\mathrm{R}(P<0.0001)$. Mean satisfaction scores were 2.06 and 2.66 in the bupivacaine and ropivacaine group respectively $(P<0.0084)$.Surgeon satisfaction score were 2.23 and 2.63 in the bupivacaine and ropivacaine group respectively $(P<0.0235)$. Rescue analgesia was needed early in the bupivacaine group.

Conclusion: There has been growing interest in regional nerve block techniques in recent era with significant results on efficacy, as they decrease the requirement of supplemental analgesia. TAP block is a very effective technique with excellent efficacy after various abdominal surgeries including cesarean section.
\end{abstract}

Keywords: TAP block, Bupivacaine, Ropivacaine.

\section{Introduction}

It is important for parturient to have less pain and to ambulate early in order to prevent venous thrombosis and to facilitate child care. Various types of analgesics via different routes are available for this purpose and also some combinations are used via different anesthetic technique. As a part of a multimodal analgesic regimen, opioids are required initially to achieve effective analgesia. Though, opioids are allied with dose-dependent side-effects including pruritus, nausea, vomiting, sedation and respiratory depression. Therefore, the ideal techniques and analgesic regimen that diminish the post-cesarean pain and the requirement of opioids has been a target of research in obstetric analgesia. ${ }^{1,2}$

Transversusabdominis plane (TAP) block is a recently defined nerve block technique which can be used for surgery comprising lower abdominal wall. ${ }^{2}$ TAP block is performedvia a blind technique based on surface anatomy landmarks ${ }^{1,2}$ by injecting local anesthetic agents into the neuro-fascial plane which lies between the transversusabdominisand the internal oblique muscles and, recently an ultrasound (US)-guided technique under direct vision. ${ }^{3,4}$ The TAP block is now included in multimodal analgesic regimen following cesarean section delivery as an effective and important technique for providing analgesia without the need of the opioids. ${ }^{5}$

Various local anaesthetic agents have been used for postoperative analgesia using ultrasound guided TAP block. ${ }^{1,2}$ Because ultrasound machines are not available in peripheral institutes in our country blind methods of transversusabdominis plane block was used. Although ropivacaine (S-enantiomer of bupivacaine) and bupivacaine (long acting Amidelinked LA) has similar pKa and plasma protein binding property and are most commonly used as LA agent for the TAP block. They have never been compared for their relative effectiveness and efficacy. The study aim was to find whether ropivacaine with its inherent advantages (anaesthetic potency, long duration of action, favorable toxicity profile) is better than bupivacaine in providing postoperative analgesia when used for TAP block in patients undergoing cesarean section.

\section{Materials and Methods}

Study design was a prospective, randomized, controlled, double blind clinical study of 6 months duration. After taking approval from Institutional Review Board (IRB) and informed written consent from the patient, this randomized controlled, double blind clinical study was carried out in 60 patients in the department of Anaesthesiology. After thorough preanaesthetic evaluation patients were included or excluded according to following criteria:

\section{Inclusion Criteria}

Informed written consent for participation in study, age: 20-35 years, pregnant patients scheduled for elective or non- 
urgent lower segment caesarean section, American society of anaesthesiology physical status I and II.

\section{Exclusion Criteria}

Patients not giving consent, contraindications to spinal anaesthesia like local infection at the site of lumbar puncture, any bleeding disorders, thrombocytopenia, space occupying lesions of the brain, anatomical disorders of the spine, hypovolaemia, allergy to local anaesthetic drugs and non-steroidal anti-inflammatory drugs, Patient on any form of analgesics therapy, body mass index $\geq 25 \mathrm{~kg} / \mathrm{m}^{2}$

Patients were randomly divided in two groups of 30 patients each by computer generated random no. method. The investigator who gave the drug and the observer were blinded to all allocation and drug related procedure. Group B $(n=30)$ - received TAP block with $15 \mathrm{ml}$ of $0.25 \%$ Inj. Bupivacainebilaterally and Group $\mathrm{R}(\mathrm{n}=30)$ - received TAP block with $15 \mathrm{ml}$ of $0.25 \%$ inj. Ropivacaine bilaterally.

In preanaesthetic preparation room, standard monitoring for Heart Rate (HR), Peripheral oxygen saturation ( $\mathrm{SpO} 2)$ Non Invasive Blood Pressure (NIBP), were established and baseline vital parameters were recorded then peripheral intravenous line was secured with $18 \mathrm{G}$ venous cannula in non-dominant hand. Pre-loading was done with Ringer Lactate $(10 \mathrm{ml} / \mathrm{kg}$ body weight) before starting the surgery and were received subarachnoid block with $2 \mathrm{ml}$ of $0.5 \%$ heavy hyperbaric inj.bupivacaine in L3L4 Inter spinous space with $23 \mathrm{G}$ spinal needle. Surgery started after achieving adequate sensory and motor block. At the end of surgery, bilateral TAP block as given. With the patient lying supine position, the iliac crest was palpated from anterior to posterior until latissimusdorsi muscle insertion would be felt. Triangle of Petit would be located (anteriorly bounded by external oblique and posteriorly by latissimusdorsi muscle and inferiorly by iliac crest). A 22 gauge $9 \mathrm{~cm}$ long blunt tip regional anesthesia needle were inserted in the triangle of Petit just above the iliac crest at right angle to the coronal plane until first resistance was felt. This indicated that the needle tip pierced external oblique muscle. The needle was further advanced gently in the same direction until "pop" sensation was felt, which signaled entry into facial plane between external and internal oblique muscles. Further advancement resulted in 2nd "pop" and this indicated entry into transverse abdominis plane. After careful negative aspiration $15 \mathrm{ml}$ of $0.25 \%$ Bupivacaine (group B) was slowly injected in $5 \mathrm{ml}$ incremental doses. The block was given on the other side using the same method. In the group $\mathrm{R}, 15 \mathrm{ml}$ of $0.25 \%$ ropivacaine (group $\mathrm{R})$ was slowly injected in $5 \mathrm{ml}$ incremental doses. The block was given on the other side using the same method. In all the patients, Incision site was covered with a pressure dressing and was shifted to Post Anaesthetic Care Unit (PACU). Patient received standard analgesia according to obstetric department protocol consisting inj. Diclofenac sodium $75 \mathrm{mg}$ intravenous 8 hourly, first dose was given at the end of surgery.(i.e. time 0 ).

The assessment of presence and severity of pain (both at rest and on passive Flexion of hip and knee) was measured immediately and after transfer to PACU\& at 30 minutes, 2, 4, 6, 8, 10,12,16, 20 and 24 hours after completion of surgery. Pain severity was measured by Visual Analog Scale (VAS $0=$ No pain, $10=$ Worst pain). At any point of time if $\mathrm{VAS}$ was $\geq 4$, intravenously Paracetamol $1 \mathrm{gm}$ was given slowly to the patient as a rescue analgesic.

\section{Outcome Measures}

Primary outcomes were Visual analogue scale (VAS) for pain score. Total dose and frequency of rescue analgesics required in 24 hours and secondary were effect on hemodynamic variables like Heart Rate (HR), Mean Arterial Pressure (MAP), Oxygen saturation ( $\mathrm{SpO} 2)$, side effects \& complications if any. Statistical analysis was done by Graph pas demo version 3.0 and test applied were man Whitney $\mathrm{U}$ test and unpaired t test.

\section{Result}

All 60 patients enrolled successfully completed the study and no patient had a primary block failure. Patient characteristics in terms of age, gender, weight and were comparable among the two groups.

\section{Table 1: Age and weight distribution}

\begin{tabular}{|l|c|c|c|}
\hline & Bupivacaine & Ropivacaine & P Value \\
\hline Age (years) & $24.23 \pm 0.60$ & $24.4 \pm 0.51$ & 0.625 \\
\hline Weight $(\mathrm{kg})$ & $60.06 \pm 0.86$ & $59.63 \pm 0.74$ & 0.775 \\
\hline
\end{tabular}

VAS score was significantly less in ropivacaine group as compared to bupivacaine after LSCS $(P<0.0001)$.

Table 2: VAS Score comparison between both groups

\begin{tabular}{|c|c|c|c|}
\hline Time & $\begin{array}{c}\text { Group B } \\
\mathbf{n = 3 0} \\
\text { Mean } \pm \text { SD }\end{array}$ & $\begin{array}{c}\text { Group R } \\
\mathbf{n = 3 0} \\
\text { Mean } \pm \text { SD }\end{array}$ & P value \\
\hline 8 Hour & $3.867 \pm 1.167$ & $0.30 \pm 0.702$ & $<0.0001$ \\
\hline 10 Hour & $4.633 \pm 1.732$ & $1.90 \pm 0.994$ & $<0.0001$ \\
\hline 12 Hour & $3.833 \pm 1.053$ & $1.767 \pm 1.040$ & $<0.0001$ \\
\hline 16 Hour & $4.70 \pm 1.112$ & $3.33 \pm 0.022$ & $<0.0001$ \\
\hline 20 Hour & $4.567 \pm 1.35$ & $2.667 \pm 1.70$ & 0.0002 \\
\hline 24 Hour & $4.033 \pm 1.189$ & $2.90 \pm 2.04$ & 0.0186 \\
\hline
\end{tabular}

Patient satisfaction score with pain relief was significantly higher in the ropivacaine group. Mean satisfaction scores were 2.06 and 2.66 in the bupivacaine and ropivacaine group respectively $(P<0.0084)$. 


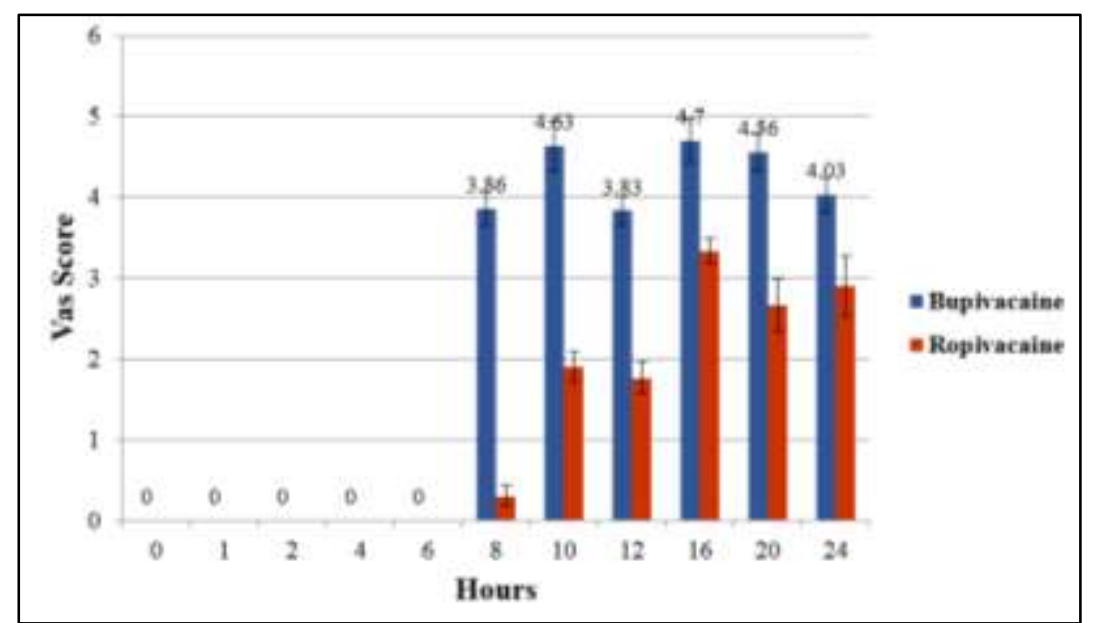

Fig. 1: VAS Score comparison between both groups

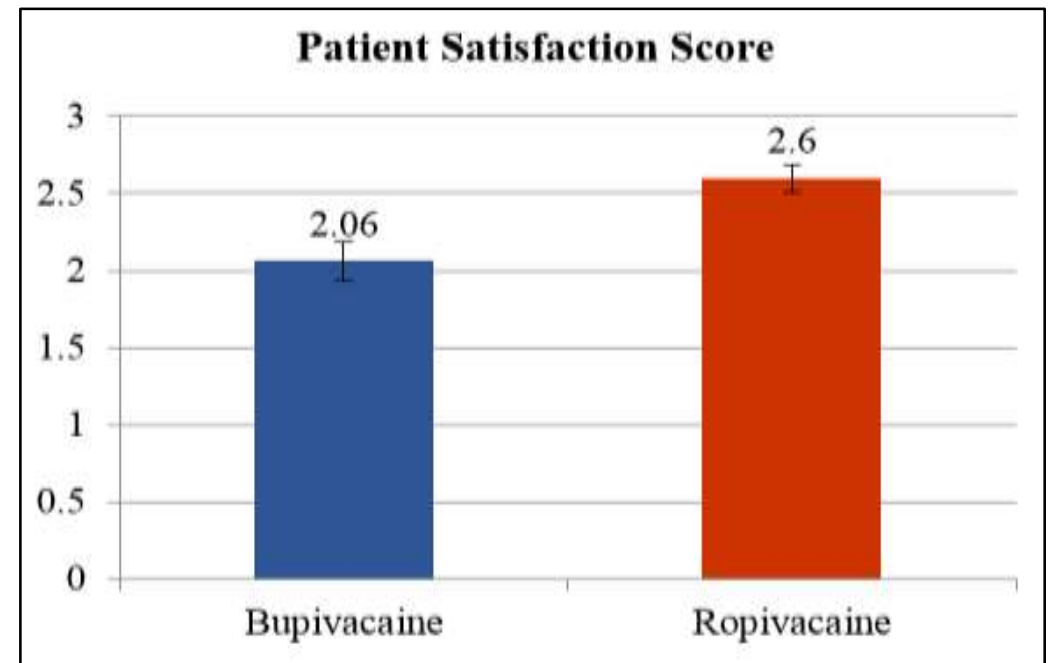

Fig. 2: Patient satisfaction score

Rescue analgesia was needed early in the bupivacaine group as compare to ropivacaine group.

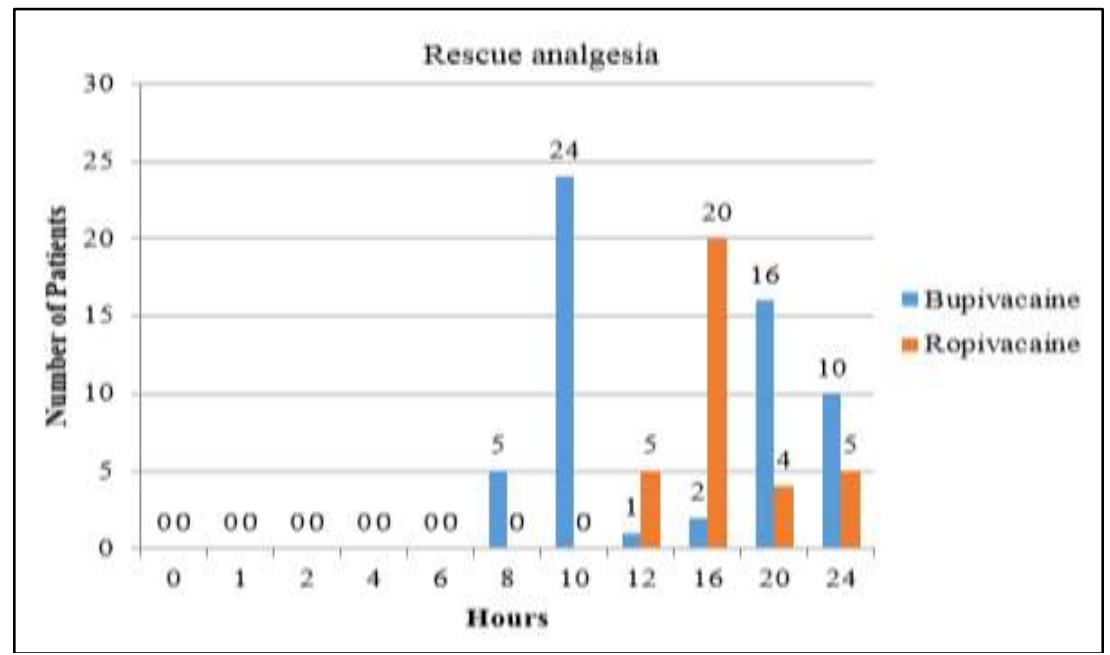

Fig. 3: Rescue analgesia

Surgeon satisfaction score were 2.23 and 2.63 in the bupivacaine and ropivacaine group respectively $(P<0.0235)$. 


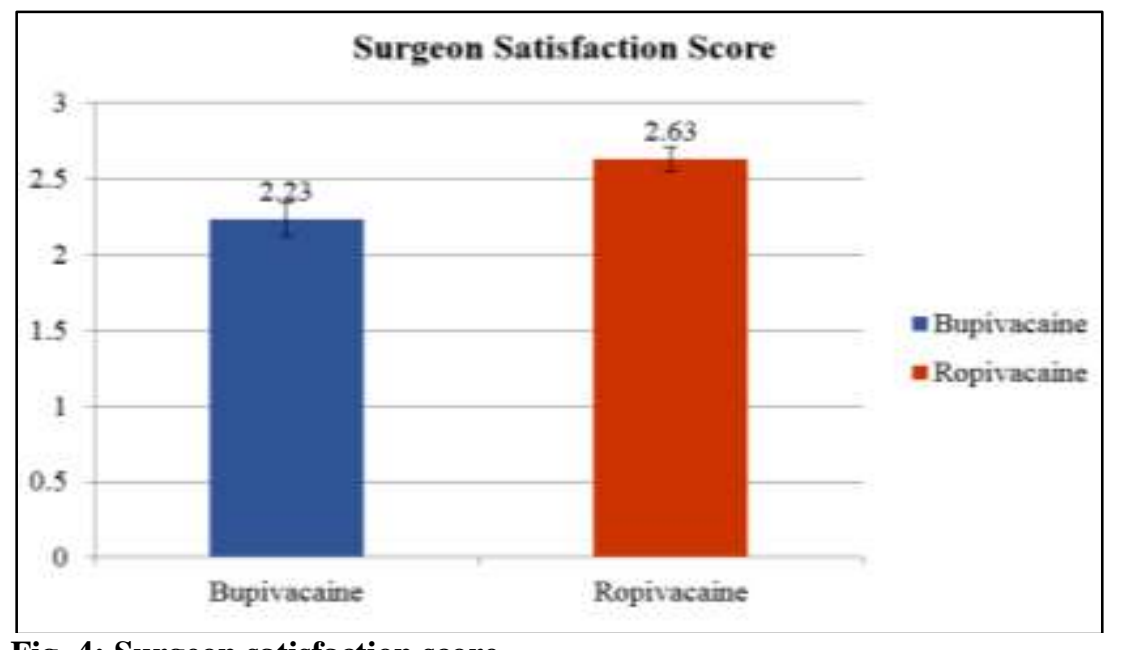

Fig. 4: Surgeon satisfaction score

Patients in both the group reported nausea and vomiting ( 2 nausea, 1 vomiting in each group). There was no local complication attributedto TAP block in either group.

\section{Discussion}

Managing pain after cesarean section is quite complex. The analgesic approach should be effective, safe and lacking of side effects. Over recent years, there has been growing interest in regional nerve block techniques with promising results on efficacy, as they diminish the requirement of supplemental analgesia. ${ }^{6}$ In the variety of regional block, TAP block is a quite new abdominal nerve block technique with excellent efficacy after a variety of abdominal surgeries including cesarean section. ${ }^{7,8}$

While comparing analgesic efficacy, in the present study VAS score was comparable in both the groups at 30 minute 2, 6 hours $(P<0.05)$. The result was comparable with the previous study done by Uma Srivastava et al., who concluded the scores were significantly lower at all time points up to 24 hours in study group both at rest and on movement $(P<0.0001)$ compared to control group. ${ }^{9}$ The study done by Maitreyi Gajanan Mankikar et al., showed VAS score was reduced after TAP block with $0.5 \%$ ropivacaine for the first $8-10$ hour postoperatively as compared to patients receiving placebo block. ${ }^{10} \mathrm{~A}$ recent Cochrane review has shown that women undergoing cesarean delivery who had local anesthetic infiltration or abdominal nerve block had reduction in the use of postoperative opioids. ${ }^{11}$ By decreasing the opioid use we can prevent the side effects and other adverse effects like nausea, vomiting which are collectively decreasing the patient satisfaction score also. Ranju Singh et al concluded that addition of clonidine $1 \mu \mathrm{g} / \mathrm{kg}$ to $20 \mathrm{ml}$ bupivacaine $0.25 \%$ in TAP block bilaterally for cesarean section significantly increases the duration of postoperative analgesia, decreases postoperative analgesic requirement, and increases maternal comfort compared to $20 \mathrm{ml}$ of bupivacaine $0.25 \%$ alone. ${ }^{12}$

To compare rescue analgesic requirement in the present study, the number of patients requiring rescue analgesics at time interval is less in ropivacaine group as compare to bupivacaine group which was statistically significant. Study done by Uma Srivastava et al., showed requirement of rescue analgesia was reduced in study group as compared to control group and difference was statistically significant $(P<0.0001) .{ }^{9}$ While comparing patient's and surgeon's mean satisfaction score, in the present study patient's mean satisfaction score were statistically significant for ropivacaine as compare to bupivacaine.

\section{Conclusion}

To conclude, we observed that the analgesic effect of TAP block with ropivacaine was more effective compared to bupivacaine. TAP block is easy technique to overcome the pain after caesarean section.

\section{Conflict of Interest: None.}

\section{References}

1. McDonnell JG, O'Donnell B, Curley G, Heffernan A, Power C, Laffey JG. Theanalgesic efficacy of transversusabdominis plane block after abdominal surgery: a prospective randomized controlled trial. Anesth Analg 2007;104:193-7.

2. McDonnell JG, Curley G, Carney J, Benton A, Costello J, Maharaj CH, Laffey JG. The analgesic efficacy of transversusabdominis plane block after cesareandelivery: a randomized controlled trial. Anesth Analg 2008;106:186-91.

3. Belavy D., Cowlishaw P.J., Howes M., Phillips F. Ultrasoundguided transversus abdominis plane block for analgesia after Caesarean delivery. Br J Anaesth 2009;103(5):726-30.

4. Kanazi GE, Aouad MT, Abdallah FW, Khatib MI, Adham AM, Harfoush DW, Siddik-Sayyid SM. The analgesic efficacy of subarachnoid morphine in comparison with ultrasoundguided transversusabdominis plane block after cesarean delivery: a randomized controlled trial. Anesth Analg 2010;111:475-81.

5. Abdallah FW, Halpern SH, Margarido CB. Transversusabdominis plane block for postoperative analgesia after Caesarean delivery performed under spinal anaesthesia? A systematic review and meta-analysis. $\mathrm{Br} J$ Anaesth 2012;109:679-87. 
6. Petersen PL, Mathiesen O, Torup H, Dahl JB. The transversusabdominis plane block: a valuable option for postoperative analgesia? A topical review. Acta Anaesthesiol Scand 2010;54:529-35.

7. Baaj JM, Alsatli RA, Majaj HA, Babay ZA, Thallaj AK. Efficacy of ultrasound-guided transversusabdominis plane (TAP) block for postcesarean section delivery analgesia - A double-blind, placebo-controlled, randomized study. Middle East J Anaesthesiol 2010;20:821-6.

8. Sriramkes B, Sahoo N, Panigrahi S. Analgesic efficacy of ultrasound guided transverse abdominis plane block following cesarean section. Int J Perioper Ultrasound Appl Technol $2012 ; 1: 5-8$

9. Srivastava U, Verma S, Singh TK, Gupta A, Saxsena A, Jagar $\mathrm{KD}$, et al. Efficacy of transabdominis plane block for post cesarean delivery analgesia: A double-blind, randomized trial. Saudi J Anaesth 2015;9:298-302.

10. Mankikar MG, Sardesai SP, Ghodki PS. Ultrasound-guided transversusabdominis plane block for postoperative analgesia in patients undergoing caesarean section. Indian J Anaesth 2016;60:253-7.
11. Bamigboye AA, Hofmeyr GJ. Local anaesthetic wound infiltration and abdominalnerves block during caesarean section for postoperative pain relief. Cochrane Database Syst Rev 2009; (3):CD006954.

12. Singh R, Kumar N, Jain A, Joy S. Addition of clonidine to bupivacaine intransversus abdominis plane block prolongs postoperative analgesia after cesarean section. J Anaesthesiol Clin Pharmacol 2016;32:501-4.

How to cite this article: Parmar $\mathrm{R}$, Bhut $\mathrm{C}$, Trivedi $\mathrm{L}$, Parmar P, Parikh RM. Clinical evaluation of efficacy and safety of transversus abdominis plane block with bupivacaine and ropivacaine for post-operative analgesia following lower segment caesarean section: A prospective, randomized, controlled, double blind study. Indian J Clin Anaesth 2019;6(2):189-93. 